\title{
Ayak Bileği Burkulması Sonrası Naviküler Kırığı Taklit Eden Aksesuar Naviküler Kemik
}

\section{Accessory Navicular Bone Mimicking Navicular Fracture after Ankle Sprain}

\author{
Muharrem ÇIDEM, Murat ULUDAĞ*, Kerem GÜN*, Ülkü AKARIRMAK* \\ Bağcılar Eğitim ve Araştırma Hastanesi, Fizik Tedavi ve Rehabilitasyon Kliniği, Istanbul, Türkiye \\ *Istanbul Üniversitesi Cerrahpaşa Tıp Fakültesi, Fiziksel Tıp ve Rehabilitasyon Anabilim Dall, Istanbul Türkiye
}

Özet

Aksesuar naviküler kemik (ANK) normal ayakta \%10-30 oranında görülür. Radyografik görünüme göre ANK'nin morfolojik sınıflaması 3'e ayrılır. En semptomatik ANK Tip 2'dir. Ayak bileği burkulmasının tanı ve tedavisi genellikle basit olmasına rağmen ANK ile birlikte bulunduğunda kırık tanısı alabilir. Biz de ayak bileği burkulmasına bağlı ağrı ve şişlik sonrası naviküler kırık olarak değerlendirilerek alçıda kalan ve eklem hareketlerinde kısıtlılık gelişen Tip 2 ANK'li 20 yaşında bir erkek hastayı sunuyoruz. Türk Fiz Tip Rehab Derg 2011;57:172-4.

Anahtar Kelimeler: Aksesuar naviküler kemik, ayak bileği burkulması, naviküler kırık

\section{Summary}

An accessory navicular bone (ANB) is present in $10-30 \%$ of normal feet. A morphological classification of ANB on the basis of the radiographic appearance distinguishes three types. Most symptomatic ANBs are of type 2. Although the diagnosis and treatment of sprained ankle are generally straightforward, together with an ANB, it might be misdiagnosed as a fracture. We present a 20-year-old male with type 2 ANB who was misdiagnosed as navicular fracture following sprained ankle. Turk J Phys Med Rehab 2011;57:172-4.

Key Words: Accessory navicular bone, ankle sprain, navicular fracture

\section{Giriş}

Ayağın aksesuar kemikleri kemikleşme sırasında gelişen anomalilerdir. Aksesuar naviküler kemik (ANK), normal ayakta \%10-14 oranında görülebilmektedir $(1,2)$. Türk toplumunda \%11,7 oranıyla ayaktaki en sık aksesuar kemik olarak bildirilmiştir (3). Otozomal dominant olarak geçiş gösterir (4). Bauhin ilk kez 1605'te bir ANK tanımladı. 1606 yılında ise Haglund naviküler kemiğe bitişik olan ve önce bir kırık olduğu düşünülüp daha sonra ANK kemik olduğu saptanan bir olguyu bildirdi (2). Radyografik görünüme göre $A N K^{\prime}$ nin morfolojik sınıflaması 3'e ayrılır. En semptomatik ANK Tip 2'dir $(5,6)$.

Ayak bileği burkulması, aktif genç ve genç erişkinlerde görülen sık bir muskuloskeletal hasardır. Ayak bileği burkulması tüm spor yaralan- malarının \%38-45'ini oluşturan spor sırasındaki en sık yaralanmadır (7). Tip 2 ANK ve esas naviküler kemik arasındaki fibrokartilajinöz bir yapı olan sinkondrozda ayak bileği burkulması sonrası hasar oluşması özellikle genç hastalarda semptomlara yol açabilir. Hastalar genellikle ayak medial kısmında egzersiz sonrası kötüleşen tekrarlayıcı ağrılardan şikayet eder (6). Tip 2 ANK, bir ayak bileği burkulması sonrası naviküler kemiğin kopma kırı̆̆ı ile karıştırılabilir $(1,8,9)$.

$\mathrm{Bu}$ yazıda, ayak bileğinin inversiyon yaralanması sonrası sağ ayak bileği çevresinde ağrı ve şişlik gelişmesi üzerine naviküler kırık olarak değerlendirilerek 1,5 ay alçıda kalan ve semptomlarında düzelme olmayan ve ayak bileği hareketlerinde kısıtılık gelişen Tip 2 ANK'li 20 yaşında bir erkek hastanın tıbbi hikaye ve uygulamalarını paylaşmayı amaçladık. 


\section{Olgu}

Yirmi yaşında erkek hasta, sağ ayak bileğinde ağrı ve hareket kısıtlılı̆ı şikayetiyle kliniğimize başvurdu. Hasta ilk defa iki ay önce koşarken sağ ayak içe doğru zorlanmış, ayak bileğine yakın ayak iç bölgede şişlik ve ağrı gelişmiş, ayak dış bölgede herhangi bir şikayeti yokmuş. Bir ortopedi kliniğine başvurmuş ve çekilen radyografide kırık olduğu söylenerek sağ ayağı alçıya alınmış (Resim 1). Hastanın alt ekstremitesi bir ay alçıda kalmış, ağrısının devam etmesi üzerine kırığın iyileşmediği söylenerek sağ ayak tekrar alçıya alınmış ve 15 gün daha alçıda tutulmuş.

Hastanın ağrıları daha da şiddetlenmiş ve ciltte parlaklık, ısı artışı, tüylenmede artış, ayak bilek eklem hareketlerinde kısıtııık oluşması üzerine hasta fiziksel tıp ve rehabilitasyon polikliniğine sevkedilmiş. Fizik muayene sırasında hasta sağ ayak üzerine basmakta ve yürümekte zorluk çekiyordu ve ayak sırtı palpasyonu ağrılıydı. Sağ ayak medial tarafta presyonla ağrısı ve ciltte parlaklık, kuruluk ve hafif ödem vardı; aktif sağ ayak bilek plantar fleksiyonu 20음 ărılı,

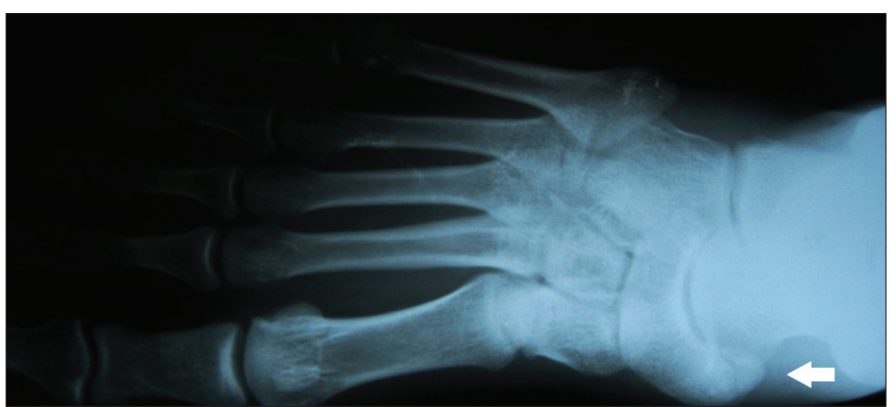

Resim 1. Sağ ayak ön-arka grafide kırık benzeri görüntü veren aksesuar naviküler kemik.

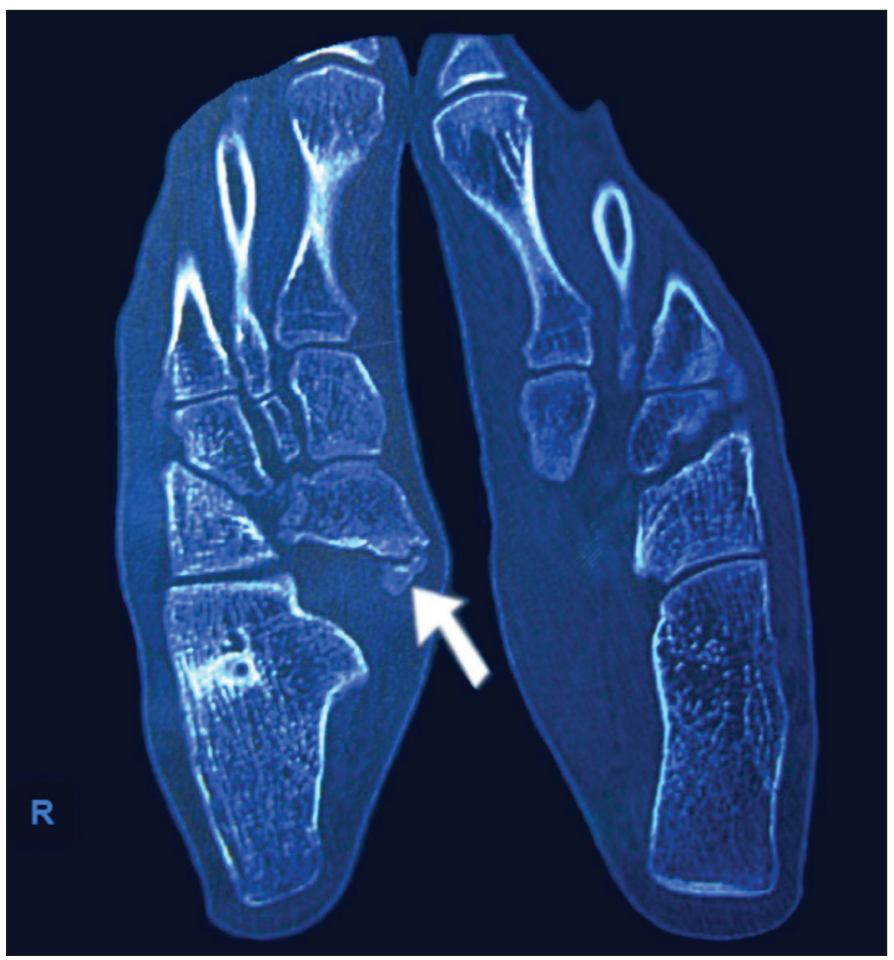

Resim 2. Burkulmuş sağ ayağın bilgisayarlı tomografi incelemesinde tip 2 aksesuar naviküler kemik. dorsifleksiyonu $15^{\circ}$ ağrılı, eversiyon ve inversiyon $5^{\text {o }}$ ve ağrılıydı Hastanın hemogram, sedimentasyon ve CRP'yi de içeren laboratuvar bulgularında özellik yoktu. Sağ ayak ön arka ve yan grafide kırık hattı olarak düşünülen naviküler kemikteki lezyona yönelik ileri görüntüleme yöntemi olarak bilgisayarlı tomografi istendi.

Sağ ayak bilgisayarlı tomografi (BT) incelemede tip 2 aksesuar naviküler kemik saptandı (Resim 2). Sol ayak BT incelemede ise tip 1 ANK saptandı (Resim 3). Hasta yatırılarak medikal olarak diklofenak

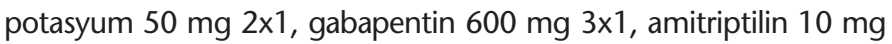
1x1 başlandı, eklem hareket açıklığı ve germe egzersizleri ile kontrast banyo 15 seans boyunca uygulandı. Illk haftadan itibaren ağılarının azalması üzerine gabapentin dozu kademeli olarak azaltılarak kesidi. Tedavi sonucunda hastanın ağrısı tamamen geçti, daha rahat yürümeye başladı ve eklem hareketleri aktif sağ ayak bilek plantar fleksiyonu 35a ağrılı, dorsifleksiyonu $25^{\circ}$ ağrılı, eversiyon ve inversiyon $10^{\circ}$ olmak üzere tama yakın iyileşti. Hasta beş aydır herhangi bir klinik şikayeti olmaksızın takip edilmektedir.

\section{Tartışma}

Aksesuar kemiklerin nadir oldukları düşünülmesine rağmen 1000 asemptomatik ayağın \%36'sında 21 farklı aksesuar kemik ortaya konmuştur. Aksesuar kemikler travma sonrası akut veya kronik ayak ağrısına neden olabilir. Ayak problemlerinin doğru tanı ve tedavisinde aksesuar kemiklerin yerleşimini bilmek önemlidir (1).

Tüm ANK'nın yaklaşık \%30'u Tip 1, \%50-60'ı ise Tip 2'dir. Naviküler kemiğin sekonder kemikleşme merkezi Tip 2 ANK'nin nedenidir. Oval veya sirküler olan Tip 1'e benzemeyerek Tip 2 ANK 12 mm kadar büyüklüğe ulaşabilen triangüler veya kalp şeklinde ortaya çıkar. Boynuzumsu veya gorilliform olarak da bilinen Tip 3,

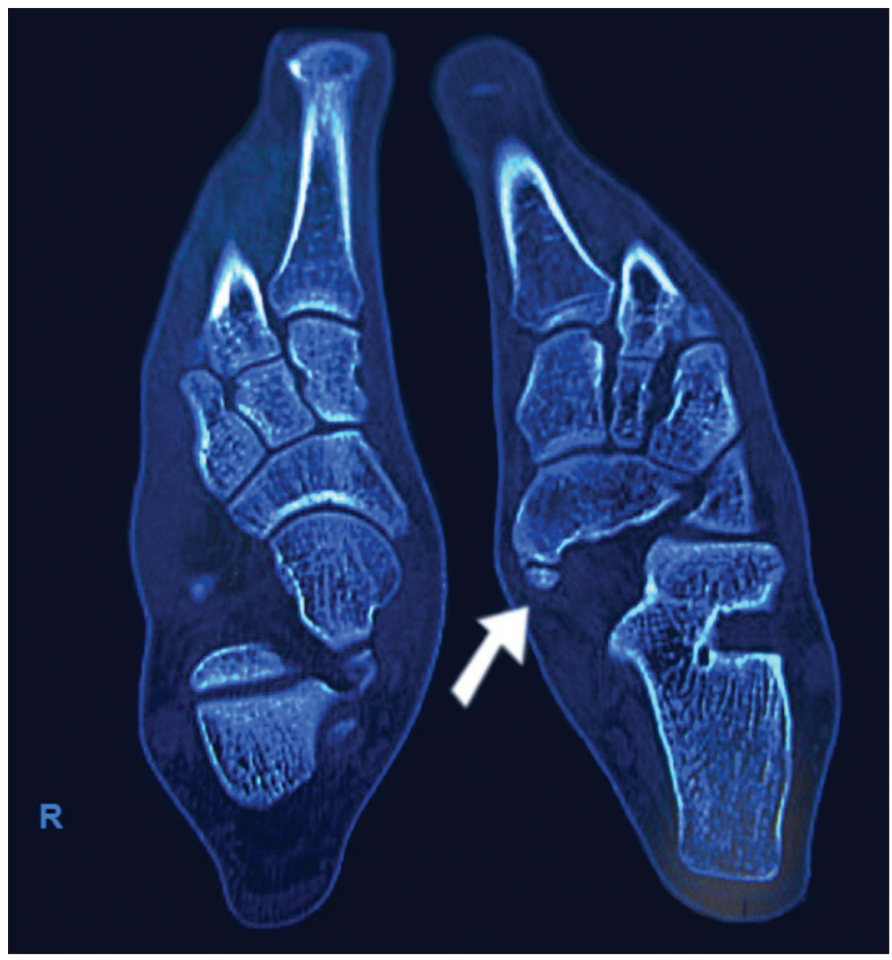

Resim 3. Sol ayak bilgisayarlı tomografi incelemede tip 1 aksesuar naviküler kemik. 
tuberositasla aksesuar kemikleşme merkezinin kemik füzyonundan oluşan çok belirgin naviküler çıkıntı ile karakterizedir $(2,5)$.

ANK'li çoğu hasta asemptomatiktir, ancak direkt travma veya ayak bileği burkulması sonrası naviküler kemiğe fibrokartilajinöz yapışma yerinde inflamasyon ve yırtığa yol açarak semptomatik olarak karşımıza çıkabilir. Ağrılı ANK'ler travma bulgusu olmaksızın bile genç aktif kadınlarda daha sık bildirilmiştir. Çocuklarda da yine sık olarak bildirilmektedir $(1,5,8)$.

Hastalar ayak iç tarafında ağrıyla başvurur. Ağrı yük vermeyle kötüleşir. En ayırdedici özellik naviküler kemik bölgesinde palpe edilebilen lokalize duyarılıktır. Genellikle aynı bölgede bir kabarılık ve kırmızlık vardır. ANK'nin öncelikli ayıııcı tanısı naviküler kemiğin medial taraf kırı̆ı̆dır. Bu kırık genellikle zorlu eversiyonla yüksekten düşmeden kaynaklanır. ANK'ye zıt olarak kırıkla ilişkili duyarlıık daha yaygındır ve ayağın iç kısmında genellikle ekimoz vardır (1). Bizim hastamız bir inversiyon yaralanması bildiriyordu. Ilk travmadan sonra hasta ayak ve ayak bileği çevresinde belirgin bir morarma ve ekimozdan bahsetmedi. Sadece ayak iç tarafta hafif bir kırmızlık ve dokunmakla hassasiyet olduğunu ifade etti. Gerek bir inversiyon yaralanması olması gerekse de ekimoz anamnezi olmaması ve presyonla daha hafif hassasiyet ve ağrı bildirmesi bizi naviküler kemik kırığından uzaklaştırmaktadır.

ANK'de oblik grafi istemek gerekir. ANK'ye rutin ön arka ve yan ayak grafisinde genellikle yanlış tanı konulduğu bildirilmektedir. Romanowski ve ark. (8) direkt grafide naviküler kııı tanısı konulan 4 hastanın takip görüntülerinde ANK'ye sahip olduğu ve kııı tanısının yanlış olduğunu belirtmişlerdir. Otuz dokuz ANK'yi içeren başka bir çalışmada tanı öncesi ortalama semptom süresinin 15 ay olduğu gösterildi. Standart ön arka ve yan grafisi de çekilen hastalarda ANK tanısı gözden kaçırılmıştı (9). Requejo ve ark. (1) da ANK'li bir hastanın doğru tanı konulana kadar yaklaşık bir yıl boyunca belirgin ayak ağrısı ve hareket kısıtılığı şikayeti ile takip edildiğini bildirmiştir.

Tanısal ultrasonografi semptomatik Tip 2 ANK'de bir sinkondroz yırtığını gösterebilir veya yumuşak doku tutulumunu saptamaya yardım edebilir. Kemik sintigrafisi ağrılı ANK'nin tanısında yüksek duyarllılk düşük özgüllüğe sahiptir. Manyetik rezonans görüntüleme (MRG), hem kemik iliği hem de yumuşak doku ödemini gösteren ağrılı ANK'nin tanısı için en yüksek duyarlıık ve özgüllüğe sahiptir. BT ise naviküler kırıkla ayıııı tanıda kemik yapıyı değerlendiren önemli bir görüntüleme tekniğidir (1). Olgumuzda semptomatik sağ ayakta kırkk olarak değerlendirilen görüntünün aksesuar naviküler kemiğe ait olduğu BT incelemesi ile gösterilmiştir. Sağ ayak ön-arka grafide ilk başta bir naviküler kırrğa benzeyen görüntünün sağ ayak BT incelemesinde bir aksesuar naviküler kemik olduğu gösterildi. Tanısal USG veya $M R G^{\prime}$ de olası sinkondroz yırtığı ve eşlik eden yumuşak doku yaralanması bulguları da görülebilirdi. Daha erken görüntüleme randevusu verilmesi ve kemik yapıyı daha iyi göstermesi nedeniyle kırıkla ayıııı tanıda BT incelemesi tercih edilmiştir.

ANK ayırıcı tanısında naviküler kırık ile birlikte, posterior tibial tendon disfonksiyonu, deltoid ligaman hasarı ve tarsal tünel sendromu da akılda tutulmalıdır $(1,7,8)$. Bizim olgumuzda tendon boyunca ağrı ve şişlik olmaması posterior tibial tendon disfonksiyonu tanısını dışlamamıza yol açtı; ayak bileği inversiyon yaralanması olması deltoid ligaman hasarından, ayak tabanında uyuşma olmaması tarsal tünel sendromu tanısından uzaklaştırdı.

Klinisyenler, travma sonrası ayak ağıısının ayıııı tanısında aksesuar kemiklerin farkında olmalıdır. Özellikle spor yaralanmaları sonrası, naviküler kemik kııı̆ı̆ ile karıştırılarak önemli morbiditelere yol açabildiğinden dolayı aksesuar naviküler kemiğin erken tanısı önemlidir.

\section{Kaynaklar}

1. Requejo SM, Kulig K, Thordarson DB. Management of foot pain associated with accessory bones of the foot: two clinical case reports. I Orthop Sports Phys Ther 2000;30:580-91.

2. Issever AS, Minden K, Eshed I, Hermann KGA. Accessory navicular bone: when ankle pain does not originate from the ankle. Clin Rheumatol 2007;26:2143-4.

3. Coskun N, Yuksel M, Cevener M, Arican RY, Ozdemir H, Bircan, et al. Incidence of accessory ossicles and sesamoid bones in the feet: a radiographic study of the Turkish subjects. Surg Radiol Anat 2009;31:19-24.

4. Kiter E, Erduran M, Gunal I. Inheritance of the accessory navicular bone. Arch Orthop Trauma Surg 2000;120:582-3.

5. Bernaerts A, Vanhoenacker FM, van de Perre S, De Schepper AM, Parizel PM. Accessory navicular bone: not such a normal variant. JBR-BTR 2004;87:250-2.

6. Chen Y], Hsu RW, Liang SC. Degeneration of the accessory navicular synchondrosis presenting as rupture of the posterior tibial tendon. J Bone Joint Surg Am 1997;79:1791-8.

7. Walia KS, Muser DE, Raza SS, Griech T, Khan YN. A management of early CRPS caused by ankle sprain: a case report. Pain Practice 2004;4:303-6.

8. Romanowski CA, Barrington NA. The accessory navicular- an important cause of medial foot pain. Clin Radiol 1992;46:261-4.

9. Grogan DP, Gasser SI, Ogden JA. The painful accessory navicular: a clinical and histopathological study. Foot Ankle 1989;10:164-9. 